$$
\text { DUE/OR/21400--T483 }
$$

\section{orin}

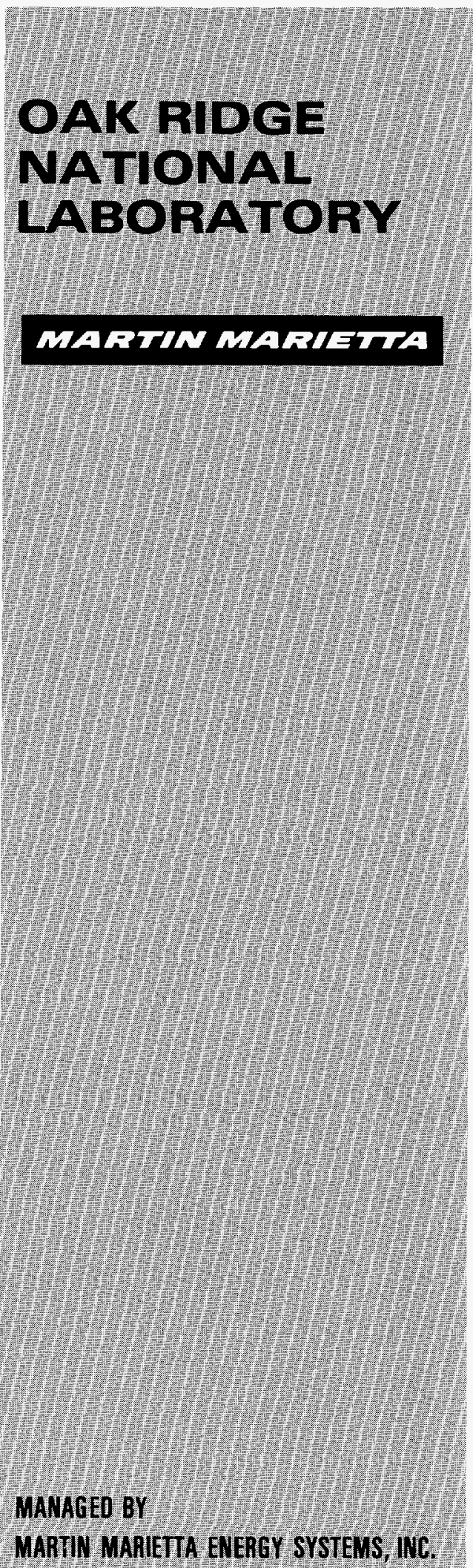

CRADA Final Report
for
CRADA Number ORNL91-0063

Oak Ridge National Laboratory

Vitro Corporation

Approved for public release; distribution is unlimited. 


\section{DISCLAIMER}

Portions of this document may be illegible in electronic image products. Images are produced from the best available original document. 
MARTIN MARIETTA ENERGY SYSTEMS, INC.

November 28, 1994

Mr. Peter D. Dayton

Director, Procurement and Contracts

Department of Energy, Oak Ridge Operations

Post Office Box 2001

Oak Ridge, Tennessee 37831-2001

Dear Mr. Dayton:

Final Report for CRADA No. ORNL91-0063 with Vitro Corp.

The subject CRADA has been completed and enclosed is the Final Report for this project.

This report does not contain proprietary information or Protected CRADA Information.

Neither Energy Systems nor the participant object to public distribution of this report.

If you have any questions, please feel free to contact me.

Very truly yours,

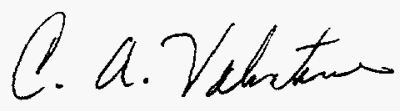

Brian Bovee

Business Manager

Office of Technology Transfer

BBB:cav

Enclosure - As Stated.

cc: File - RC 


\title{
Final Report on the Vitro CRADA
}

\author{
Computing Applications Division \\ Oak Ridge National Laboratory \\ Oak Ridge, Tennessee
}

February 1994

\begin{abstract}
Prepared for
U.S. Department of Energy

Office of Environmental Restoration and Waste Management under budget and reporting code EW 20
\end{abstract}

\section{MARTIN MARIETTA ENERGY SYSTEMS, INC. managing the}

Oak Ridge K-25 Site

Oak Ridge y-12 Plant

Oak Ridge National Laboratory

under contract DE-AC05-84OR21400
Paducah Gaseous Diffusion Plant Portsmouth Gaseous Diffusion Plant under contract DE-AC05-76OR00001

for the

U.S DEPARTMENT OF ENERGY

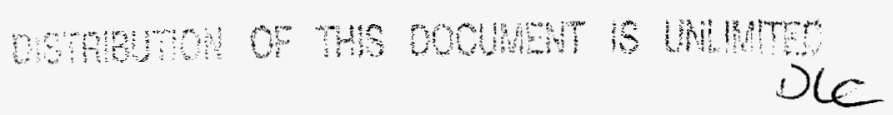




\title{
DRAFT
}

\author{
FINAL REPORT ON THE VITRO CRADA
}

February 12, 1994

\begin{abstract}
:
In February 1992 ORNL and Vitro Corporation of Silver Spring, Maryland entered into a Cooperative Research and Development Agreement (CRADA). The CRADA contained a list of planned research activities for a specified two year period. During the life of the CRADA, ORNL and Vitro investigated the application of advanced Geographic Information System (GIS) technologies to site characterization and environmental remediation work. The six CRADA tasks were to 1) conduct feasibility studies for integrating GIS tools with DBMS, graphics, and other packages to aid in environmental analyses, 2) develop environmental and geographic data standards and guidelines including data structures, quality assurance practices, and metadata, 3) investigate environmental and remediation predictive modeling and their integration with GIS, 4) study remote sensing techniques including integration of GIS data and image analysis results, 5) test advanced field stations for GIS data collection including Global Positioning Systems (GPS) techniques, and 6) investigate display enhancement techniques including 2D/3D visualization coupled with GIS data bases. The CRADA was a success and has provided knowledge and experience which both parties can continue to exploit.
\end{abstract}

\section{BACKGROUND:}

In February 1992 ORNL and Vitro Corporation of Silver Spring, Maryland entered into a Cooperative Research and Development Agreement (CRADA). The CRADA contained a list of planned research activities for a specified two year period. During the life of the CRADA, ORNL and Vitro investigated the application of advanced Geographic Information System (GIS) technologies to site characterization and environmental remediation work. This document details the research task objectives of the CRADA and work performed.

Under the terms of the CRADA, the Oak Ridge National Laboratory in cooperation with the Environmental Restoration Division was to assist Vitro in the research, development, and demonstration of advanced GIS concepts that support environmental assessment and restoration activities. ORNL researchers were to provide key experience and toois in the GIS field, appiying them to site characterization and remediation studies. Vitro was to provide extensive experience in systems engineering and software support, as well as being a testbed for implementation of a prototype system. The effort was designed to provide new and powerful techniques to enhance 


\section{DRAFT}

engineers and researchers capabilities in studying all types of environmental problems and potential solutions. It was also designed to provide managers with decision support methods to help justify and plan remediation actions.

\section{SCOPE OF WORK:}

A workplan was developed which consisted of six potential GIS-related tasks that would benefit both Vitro Corporation and Environmental Restoration (ER). The first three tasks were given high priority with an emphasis on applicability to site characterization, data management, and remediation modeling issues. These six tasks were to:

1. Conduct feasibility studies for integrating GIS tools with DBMS, graphics, and other packages to aid in environmental analyses

2. Develop environmental and geographic data standards and guidelines including data structures, quality assurance practices, and metadata

3. Investigate environmental and remediation predictive modeling and their integration with GIS

4. Study remote sensing techniques including integration of GIS data and image analysis results

5. Test advanced field stations for GIS data collection including Global Positioning Systems (GPS) techniques

6. Investigate display enhancement techniques including 2D/3D visualization coupled with GIS data bases

\section{ACTIVITY FINAL STATUS:}

\section{Feasibility Studies to Enhance GIS Integration for Environmental Analyses}

Using existing tools, a site characterization study was undertaken for one of Vitro's primary sponsors, a US Navy facility at Keyport, Washington. One purpose was to demonstrate the data flow process from initial data collection through analysis steps to final presentation for the facility. A number of different geographic variables were generated and processed including facility data, topographic and bathymetric features, and all types of environmental data and sampling areas. 


\section{DRAFT}

Additional geographic data sources provided inclusion of historical land cover, aerial photography, engineering drawings, transportation, and hazardous waste storage locations into the site characterization by Vitro. The resulting data base contained a synergistic combination of geographical and attribute data valuable to several departments within the Navy base in addition to the environmental managers. In order to facilitate the storage, analysis and visualization of these data to these departments, ORNL and Vitro researched the capabilities of various GIS tools. The ArcView GIS tool was selected to provide onbase GIS capability in a PC environment. ArcView was successfully introduced to the Navy facility and its users trained by Vitro. Recently, as Oracle became the standard RDBMS at the Navy facility, either an Oracie-compatible GIS tool was needed to replace ArcView, or ArcView needed to be enhanced.

A series of feasibility tests were started by ORNL to investigate the possibility of enhancing ArcView through the integration of four separate software packages within the Microsoft Windows operating system. The enhancement was to provide some capabilities similar to the OREIS components, though not nearly as powerful.

The four initial packages chosen for testing included:

- ArcView for GIS query, selection and map display, and for compatibility with Arc/Info being used at Vitro for data preparation and analyses and at ORNL for OREIS,

- FoxPro for the RDBMS since it had an excellent user interface and used dBase III+ type files that are used internally by PC ArcView,

- Microsoft Excel for spreadsheet capabilities and to produce 2D/3D statistical graphics under mouse control, and

- CorelDraw as a graphics editing and display package to accept and annotate any clipped window from the other three packages.

Initial feasibility testing was performed on these packages separately and integrated together under Windows by ORNL. Although the results were promising there were some limitations to this configuration. At the same time, details of an ArcView upgrade by the manufacturer were announced. ArcView 2 will have greatly improved analytical, visualization, and query capabilities in addition to being able to access Oracle databases directly.

A new RDBMS-related package became available for PCs and SUN workstations called Oracle Data Browser. It is a mouse-driven query and display package for Oracie data. 


\section{DRAFT}

The package was included in the feasibility testing to determine whether it could be a major component in an integrated system. This was attractive because many of Vitro's customers use Oracle and it is the RDBMS package being used within OREIS. The goal was to provide an easy migration path from the PC environment (for smaller Vitro users) to Unix workstations with OREIS compatibility so that the data, tools, and training are very similar.

2. Data Standards and Guidelines for Data Structures, Quality Assurance, and Metadata

This task was an important ingredient in establishing data management capabilities for both Vitro and ER. The task was divided into guidelines associated with GIS data and guidelines for the tabular environmental measurement data. Vitro took the lead in organizing, structuring, and documenting the environmental measurement data typical of their customers. They took advantage of previous data structures developed or used at ORNL. ORNL took the lead in developing the GIS guidelines since the OREIS effort has the same needs. Vitro staff attended OREIS training to learn about OREIS and the data structures employed. The result of this work will assist Vitro in establishing good data management practices for their GIS and environmental data. A GIS guideline document produced for OREIS was directly applicable to this effort.

3. Environmental and Remediation Predictive Models and their Integration with GIS

Two types of models were selected for investigation by Vitro and ORNL. ORNL was responsible for 2D and 3D spatial models such as hydro-geochemical modeling of subsurface characteristics. Results from using $3 \mathrm{D}$ tools previously developed at ORNL were employed by Vitro at their Navy customer's installation. Ancillary research at ORNL on 3D visualization for ER subsurface modeling was performed using the EarthVision package from Dynamic Graphics.

Vitro took responsibility for remediation models that will help assess alternate clean-up strategies across a site. They acquired the services of the University of Cincinnati (UC) at the EPA Center Hill Research Laboratory who have experience in this area. A remediation model, Graphical Remediation Assessment and Cost Evaluation (GRACE), was adapted to allow preliminary cost-benefit assessments of groundwater treatment linked to GIS. The operating characteristics and costs of different configurations are selected from menus on the PC screen and the well icons are placed at key locations on a digital map of a site. Groundwater movements over time are displayed and pollutant dispersions are simulated. Multiple alternatives and scenarios are allowed and costbenefit comparisons can be made graphically on the screen between different scenarios. Although the results cannot be used for final engineering design, they give a good idea as to which scenario may provide the optimum performance/cost combination. 


\section{DRAFT}

4. Remote Sensing and Image Analysis Techniques Integrated with GIS Data

ORNL took the lead in developing remote sensing and image processing techniques that can aid in environmental studies from initial identification of problem areas to long-term monitoring of clean-up improvements. Vitro assessed these results to determine optimal techniques and applications that should be implemented at Vitro to improve their market position. Of particular benefit has been the insight gained through the on-going Oak Ridge Remote Sensing and Aerial Survey programs. Some simpler image handling and display techniques were used by Vitro for use at the Navy customer's site.

The Oak Ridge flyover and support for environmental restoration problems provided excellent data, imagery, and analysis results from which to assess advanced remote sensing studies integrating GIS data and techniques. These studies involved scanned aerial photographs (color IR and natural color), Multi-Spectral Scanner (MSS) imagery useful in determining vegetation stress and landcover, thermal data to look for seeps and springs, radiation data, etc. New techniques were tested for using GPS and other control points with elevation models to create ortho-photos which register with known map projections and coordinate systems. These images can then be used to update map data bases of facilities as well as underiays for all types of thematic data. Combinations of such data in 2D and 3D aid in understanding and interpreting the thematic attribute data. Overlaying current facilities and pollutant information on historical photography can help identify old contamination sources.

\section{Field GIS Data Collection Stations including GPS Techniques}

This task was to investigate advanced systems for collecting GIS and environmental data in the field using global positioning system techniques for positional information. Three related efforts were initiated or carried out at ORNL that provided information on some potential technologies applicable for a field station. A GPS sampling effort was conducted at ORNL to gain experience in how the technology worked, what positional accuracies could be obtained, and to establish some benchmarks that would be useful in remote sensing studies later. Preliminary testing done at ORNL with special software/hardware determined whether low-cost real-time digitized video input could be captured and/or displayed on a PC-based station. This can provide a fast mechanism to capture field conditions across the landscape or at sampling stations via a small video camera that might include audio as well.

A review of available software and hardware for.integration into the field station was completed at ORNL. The resulting prototype is a PC color notebook computer running FieldNotes and real-time GPS coordinate collection. This beta software permits the display of raster and vector data while incorporating the GPS locational signal for $\mathrm{X}, \mathrm{Y}$ 


\section{DRAFT}

determination. In addition the system aiso permits data entry keyed to each new point. The system is currently being tested and is a promising geographical display and attribute entry vehicle for field data. The system has also been tested briefly in real-time vehicle tracking.

\section{Display Enhancement Including 2D/3D Visualization Coupled with GIS Databases}

This was a low-priority task to investigate improvements in visualization and animation of spatial data applicable for assessing environmental conditions. These techniques would apply 2D and 3D information that changes over time. An effort was made to install and test an animation package that had been developed by the Ohio Supercomputer Center on a Sun workstation. An ancillary effort investigating the use of the Automated Visualization System (AVS) provided preliminary results that indicated some usefulness in $3 \mathrm{D}$ terrain modeling with vector overiays.

\section{BUDGET:}

The estimated costs of the CRADA were to be divided between DoE and Vitro in the following manner:

$\begin{array}{ll}\text { Vitro Funds-In } & \$ 240,000 \\ \text { Vitro In-Kind } & \$ 400,000 \\ \text { DoE Contribution } & \$ 120,000\end{array}$

At the end of the two year life of the CRADA approximately 85 to $90 \%$ of the DoE contribution was expended. Vitro expenditures were around $\$ 75,000$ funds-in and $\$ 300,000$ in-kind. The funds-in were less than expected due to an initial delay of four months in setting up the Vitro account, an on-going accounting problem of avoiding an overrun of the up-front $\$ 30,000$ buffer, payment delays at Vitro due to installation of a new accounting system in January 1993, and due to the consequences of Vitro being sold to another parent company. The Vitro in-kind support and resources are listed in Appendix A.

\section{CONCLUSION:}

The CRADA between ORNL and Vitro Corporation was a successful venture which benefitted both parties. Vitro was able to establish a GIS diversification program, acquire and implement a prototype system using advanced technologies explored under the CRADA, and develop it into a competitive GIS laboratory. The CRADA also aided Vitro in both GIS marketing and GIS contract execution. Results from the CRADA benefitted ORNL through research in support of 


\section{DRAFT}

the CRADA, testing and development of new spatial technologies applicable to environmental restoration problems, implementation of a GPS field data collection station, and from Vitro system, engineering and marketing expertise. In addition, the GRACE model from the University of Cincinnati has the potential for incorporation into the ER environmental toolset. The experience. on the whole, was a positive one which both parties can continue to exploit for their own benefit.

\section{DISCLAIMER}

This report was prepared as an account of work sponsored by an agency of the United States Government. Neither the United States Gnvernment nor any agency thereof, nor any of their employees, makes any warranty, express or implied, or assumes any legal liability or responsibility for the accuracy, completeness, or usefulness of any information, apparatus, product, or process disclosed, or represents that its use would not infringe privately owned rights. Reference herein to any specific commercial product, process, or service by trade name, trademark, manufacturer, or otherwise does not necessarily constitute or imply its endorsement, recommendation, or favoring by the United States Government or any agency thereof. The views and opinions of authors expressed herein do not necessarily state or reflect those of the United States Government or any agency thereof. 
DRAFT

\section{APPENDIX A}

Vitro in-kind support and procurements for use in the CRADA:

- 53 person months of GIS staff

- 24 person months of GIS management

- Contract with the University of Cincinnati towards GRACE/GIS integration

- GIS library and subscriptions

- GIS lab and supplies

- GIS symposia and conferences

- $\quad$ GIS training classes

- Vitro/ORNL travel and expenses

- $\quad$ PC 80386, $33 \mathrm{MHz}, 337 \mathrm{MB}$ HD, 8 MB RAM, 80387 Math Coprocessor

- $\quad$ SVGA High-resolution monitor

- High-resolution 3' by 4' Numonics digitizing table

- $\quad$ SUN SPARCstation 2GX

- SUN SPARCstation 10GX

- $\quad$ SUN CD-ROM Reader

- $\quad$ SUN 1.2 GB HD (2)

- $\quad$ SUNPC '486 internal board

- $\quad$ Laptop PC 80486, 120 MB HD, 4 MB RAM

- US Robotics Sportster high-speed modem (2)

- Versatec color electrostatic printer lease

- $\quad$ Printer paper and chemicals

- $\quad$ AutoCAD Release 11

- $\quad$ Microsoft Windows 3.1

- $\quad$ Interactive UNIX V/386

- $\quad$ GRASS GIS Version 4.0

- $\quad$ ESRI Arc/Info GIS 6.0

- core module (2)

- Triangulated Irregular Network (TIN) module (2)

- GRID module

- $\quad$ ESRI ArcView

- $\quad$ ESRI PC ArcView (2)

- WordPerfect 5.2 for DOS

- Hi-Jack Format Conversion

- FoxPro RDBMS

- Microsoft PowerPoint

- ORACLE RDBMS modules

- $\quad$ SAS Statistical Package modules 